\title{
Simple schedule and signal-key multiple schedule responding and behavioral contrast
}

\author{
FRANCES K. McSWEENEY, JAMES D. DOUGAN, and VALERI A. FARMER \\ Washington State University, Pullman, Washington
}

\begin{abstract}
Pigeons' rates of responding on simple schedules appearing alone or as components of signalkey multiple schedules were not systematically different early in training, but were different later in training. This suggests that a simple schedule may be an appropriate baseline from which to measure behavioral contrast. Positive behavioral contrast, like the present differences between simple and multiple schedule responding, does not appear when naive subjects respond on signalkey multiple schedules, but does appear when experimentally experienced subjects are used.
\end{abstract}

Experiments in behavioral contrast frequently measure contrast relative to baseline multiple schedules that provide the same simple schedules in each of two components (e.g., a multiple VI $\times$ VI $\times$ schedule). McSweeney (1980) asked whether contrast also could be measured relative to a simple schedule baseline; that is, similar to positive contrast, responding might be faster during the more favorable component of a multiple schedule than during the same schedule appearing alone (see, e.g., Freeman, 1971; Halliday \& Boakes, 1974; Hearst \& Gormley, 1976; Jaffe, 1973; McSweeney, 1980; Pear \& Wilke, 1971). Similar to negative contrast, responding might be slower during the less favorable component than during the same simple schedule (e.g., McSweeney, 1982).

If simple schedules are appropriate baselines, then differences between simple and multiple schedule responding should appear under the same conditions that produce contrast. The present experiment examines this question for signal-key multiple schedules. Contrary to the present hypothesis, McSweeney (1980) found that the rates of responding during the more favorable components of signal-key multiple schedules were greater than the rates of responding during comparable simple schedules, even though positive contrast is usually not observed during signal-key multiple schedules. However, McSweeney's (1980) experiment used experienced subjects. Most of the studies that failed to find signal-key behavioral contrast used naive subjects (Schwartz, 1975; Spealman, 1976; White \& Braunstein, 1979; Williams \& Heyneman, 1981, Experiment 1; Woodruff, 1979) or subjects with limited experimental histories (Keller, 1974; cf. Schwartz, Hamilton, \& Silberberg, 1975). The two studies that did find contrast during signal-key multiple schedules (Schwartz, 1978; Williams \& Heyneman, 1981, Experiment 2) used subjects described as having "extensive experimental histories."

Some of these data were presented at the 1983 meeting of The Psychonomic Society. Address correspondence to F. K. McSweeney, Department of Psychology, Washington State University, Pullman, WA 99164-4830.
In this experiment, we asked whether differences between responding during simple and signal-key multiple schedules, like multiple-schedule behavioral contrast, fail to occur when naive subjects are used, but develop as subjects gain experience.

\section{METHOD}

\section{Subjects}

Three naive pigeons, maintained at $80 \%-85 \%$ of their free-feeding weights, served as subjects.

\section{Apparatus and Procedure}

We used a Grason-Stadler pigeon station, Model E6446C, enclosed in a sound-attenuating chamber. The houselight was illuminated during the sessions.

After subjects were shaped to peck the response keys, they were placed on the following series of schedules: VI $1 \mathrm{~min}$ (40); multiple VI $1 \mathrm{~min}$ VI 4 min (40); VI $1 \mathrm{~min}$ (40); multiple VI $1 \mathrm{~min}$ VI $15 \mathrm{sec}$ (50); VI 1 min (40); multiple VI 1 min extinction (ext 20); VI 1 min (40); multiple VI 1 min VI $30 \mathrm{sec}(50)$; VI 1 min (40); multiple VI 1 min VI 10 min (25); VI 1 min (40); multiple VI 1 min VI 4 min (40); and VI $1 \mathrm{~min}(40)$. (The number in parentheses after each schedule is the number of reinforcers presented per session for that schedule.) Sessions were conducted daily, five to six times per week.

Pecks on the green center key produced reinforcers. A white light illuminated the left key, whenever the VI 1-min component or schedule was available. A red light illuminated the right key during the other component. The components alternated every $90 \mathrm{sec}$.

Reinforcers (5-sec access to mixed grain) were scheduled according to a 20-interval Catania and Reynolds (1968, Appendix 2) series. Keylights were extinguished, and responses were not recorded during reinforcement.

Subjects responded on each schedule until responding stabilized. An average of 40 sessions was conducted per schedule.

\section{RESULTS}

Table 1 presents the mean rates of responding during each schedule and component. Reinforcer time was excluded from all calculations. Table 1 shows that positive contrast did not appear at first, but developed over time. A one-way within-subject ANOVA applied to the response rates during the VI 1-min components and schedules was statistically significant $[F(12,24)=4.89, p<.05]$. Until at least the final two multiple schedules, $t$ tests for 
Table 1

Rates of Responding Emitted by Naive Subjects During Simple Schedules and During the Components of Multiple Schedules

\begin{tabular}{lrrrr}
\hline & \multicolumn{3}{c}{ Subject } & \\
\cline { 2 - 5 } Schedule & \multicolumn{1}{c}{15} & \multicolumn{1}{c}{17} & Mean \\
\hline VI 1 Min & 76.4 & 71.0 & 74.3 & 73.9 \\
Mult VI 1 Min & 38.6 & 87.8 & 95.6 & 74.0 \\
VI 4 Min & 34.5 & 77.7 & 84.5 & 65.6 \\
VI 1 Min & 89.2 & 98.9 & 103.6 & 97.3 \\
Mult VI 1 Min & 51.7 & 83.4 & 98.0 & 77.7 \\
VI 15 Sec & 149.2 & 128.5 & 115.3 & 131.0 \\
VI 1 Min & 77.0 & 83.5 & 83.9 & 81.5 \\
Mult VI 1 Min & 85.7 & 136.7 & 140.1 & 120.8 \\
Ext & 32.3 & 115.9 & 121.6 & 89.9 \\
VI 1 Min & 96.7 & 130.3 & 104.8 & 110.6 \\
Mult VI 1 Min & 59.9 & 130.2 & 103.1 & 97.7 \\
VI 30 Sec & 83.2 & 143.8 & 115.3 & 114.1 \\
VI 1 Min & 70.0 & 114.3 & 82.0 & 88.7 \\
Mult VI 1 Min & 93.2 & 175.1 & 125.9 & 131.4 \\
VI 10 Min & 41.1 & 147.9 & 118.3 & 102.4 \\
VI 1 Min & 81.4 & 159.9 & 126.7 & 122.7 \\
Mult VI 1 Min & 108.2 & 177.5 & 173.2 & 153.0 \\
VI 4 Min & 103.2 & 173.4 & 167.4 & 148.0 \\
VI 1 Min & 76.3 & 113.8 & 168.2 & 119.4 \\
\hline
\end{tabular}

matched pairs showed that response rates during the more favorable VI 1-min components were not significantly greater statistically than response rates during the surrounding simple schedules. The rates of responding during the VI 1-min component of the multiple VI 1-min VI 10 -min schedule were significantly greater than the response rates during the preceding VI 1-min schedule $[t(2)=3.92, p<.05]$ and marginally greater than response rates during the following VI 1 -min schedule $[t(2)=1.79, p \approx .10]$. Response rates during the VI $1-$ min component of the second multiple VI 1-min VI 4min schedule were significantly greater than response rates during the preceding VI 1 -min schedule $[t(2)=3.55$, $p<.05$ ] and marginally greater than response rates during the following VI 1 -min schedule $[t(2)=1.98$, $.05<p<.10$ ].

Negative contrast did not occur. Response rates during the less favorable VI 1-min components were not significantly less $(p<.05)$ than those emitted during the preceding or following simple schedules for either the multiple VI 1-min VI 15-sec or multiple VI 1-min VI 30sec schedules.

\section{DISCUSSION}

The present results suggest that differences between simple schedule responding and responding during the more favorable component of a multiple schedule are examples of positive behavioral contrast. Differences between simple and multiple schedule responding did not appear troduced. The studies that did not find positive contrast using a signalkey procedure conducted many fewer sessions (Keller, 1974, mean = 122 sessions; Schwartz, 1975, 215; White \& Braunstein, 1979, 57;
Woodruff, 1979, 71; Williams \& Heyneman, 1981, Experiment 1, 115 sessions before the last multiple VI ext schedule; Spealman, 1976, 132 sessions, although 2 of his 6 subjects had previous experience). The one researcher who did find positive contrast and reported the experimental histories of the subjects (McSweeney, 1980, Experiment 3) used subjects who had responded on multiple and VI schedules for more than 1,000 sessions. Therefore, neither differences between simple and signalkey multiple schedule responding nor positive behavioral contrast occurs when subjects have had little experience, but both do develop later.

It is not known whether differences between simple schedule responding and responding during the less favorable components of multiple schedules are examples of negative contrast. Differences between simple schedule responding and responding during the less favorable component of the multiple schedule did not reach significance in either the present study or McSweeney (1980); however, negative contrast, as defined here, has rarely been studied when subjects respond on signalkey multiple schedules. The existing data show considerable variability across subjects (Schwartz, 1975, 1978). Future experiments should investigate this question.

The present results may create problems for Williams and Heyneman's (1981) argument that changes in response topography explain the absence of contrast during signal-key multiple schedules. Williams and Heyneman suggested that response topography changes from a simple peck during baseline to a look-plus-peck during contrast. This change in the efficiency of the response masks any increase in response rate that would otherwise occur and be interpreted as positive contrast.

Williams and Heyneman's (1981) argument also applies to the present experiment. The look-plus-peck during signal-key multiple schedules should be less efficient than the peck during simple schedules. Therefore, no positive contrast should be observed.

However, the present results create two problems for Williams and Heyneman's (1981) model. First, they support an alternative explanation for Williams and Heyneman's results. In their Experiment 1, Williams and Heyneman used a standard signal-key procedure and observed no contrast. In Experiment 2, they used a modified signal-key procedure that required subjects to look and peck in both the baseline and contrast phases. As predicted by their model, positive contrast appeared during Experiment 2, when differences in response topography across schedules were eliminated. However, Williams and Heyneman also used naive subjects in Experiment 1 and subjects described as having "extensive experimental histories" in Experiment 2. Therefore, differences in experience, rather than differences in response topography, might account for the different results of their Experiments 1 and 2 .

Second, Williams and Heyneman's (1981) theory does not explain why negative contrast is not usually observed for signal-key multiple schedules. The predicted decrease in the efficiency of the response should produce a decrease in response rate that should make the observation of negative contrast very likely when signal-key procedures are used. However, Schwartz (1978), McSweeney (1980, Experiment 3), and the present experiment failed to find negative contrast when either simple or signal-key multiple schedules were used as baselines. Schwartz (1975) found results that varied across subjects and that could not be unambiguously called contrast. He did not recover baseline after the contrast manipulation. Therefore, contrast could not be distinguished from fluctuations in responding over time.

Williams and Heyneman's (1981) experiment should be repeated with the experimental histories of the subjects held constant. An effect that could be more clearly attributed to response topography might be found. But, even if it were, the difficulty producing negative contrast would indicate that something more than changes in response topography is responsible for the failure to find behavioral contrast when signal-key multiple schedules are used.

\section{REFERENCES}

Catania, A. C., \& Reynolds, G. S. (1968). A quantitative analysis of the responding maintained by interval schedules of reinforcement. Journal of the Experimental Analysis of Behavior, 11, 327-383.

FrEEMAN, B. J. (1971). The role of response-independent reinforcement in producing behavioral contrast effects in the rat. Learning \& 
Motivation, 2, 138-147.

Halliday, M. S., \& BoaKes, R. A. (1974). Behavioral contrast without response-rate reduction. Journal of the Experimental Analysis of Behavior, 22, 453-462.

Hearst, E., \& Gormley, D. (1976). Some tests of the additivity (autoshaping) theory of behavioral contrast. Animal Learning \& Behavior, 4, 145-150.

JAFFE, M. L. (1973). The effects of lesions in the ventromedial nucleus of the hypothalamus on behavioral contrast in rats. Physiological Psychology, 1, 191-198.

KeLLER, K. (1974). The role of elicited responding in behavioral contrast. Journal of the Experimental Analysis of Behavior, 21, 249-257.

MCSWEENEY, F. K. (1980). Differences between rates of responding emitted during simple and multiple schedules. Animal Learning \& Behavior, 8, 392-400.

MCSWEENEY, F. K. (1982). Responding during simple schedules and during less favorable components of multiple schedules. Behaviour Analysis Letters, 2, 345-351.

Pear, J. J., \& WILKE, D. M. (1971). Contrast and induction in rats on multiple schedules. Journal of the Experimental Analysis of Behavior, 15, 289-296.

SCHWARTZ, B. (1975). Discriminative stimulus location as a determinant of negative behavioral contrast in the pigeon. Journal of the Experimen- tal Analysis of Behavior, 23, 167-176.

SCHWARTZ, B. (1978). Stimulus-reinforcer contingencies and local behavioral contrast. Journal of the Experimental Analysis of Behavior, 29, 297-308.

Schwartz, B., Hamilton, B., \& Silberberg, A. (1975). Behavioral contrast in the pigeon: A study of the duration of key pecking maintained on multiple schedules of reinforcement. Journal of the Experimental Analysis of Behavior, 24, 199-206.

SPEALMAN, R. D. (1976). Interactions in multiple schedules: The role of the stimulus-reinforcer contingency. Journal of the Experimental Analysis of Behavior, 26, 79-93.

White, K. G., \& Braunstein, S. B. (1979). Stimulus control of topographically tagged responding. Animal Learning \& Behavior, 7, 333-338.

Williams, B. A., \& Heyneman, N. (1981). Determinants of contrast in the signal-key procedure: Evidence against additivity theory. Journal of the Experimental Analysis of Behavior, 35, 161-173.

WoODRUFF, G. (1979). Behavioral contrast and type of reward: Role of elicited response topography. Animal Learning \& Behavior, 7, 339-346.

(Manuscript received for publication September 9, 1985.) 